Available online at http://journal.stkip-andi-matappa.ac.id/index.php/histogram/index

Histogram : Jurnal Pendidikan Matematika 4(1), 2020, 78 - 92

\title{
PENGEMBANGAN INSTRUMEN EVALUASI PEMAHAMAN KONSEP KALKULUS BERBASIS KOMPUTER
}

\author{
Akbar Nasrum \\ Universitas Sembilanbelas November Kolaka \\ * Corresponding Author. Email: akbar.nasrum@gmail.com \\ Received: 1 Februari 2020; Revised: 27 Februari 2020; Accepted: 30 Maret 2020
}

\begin{abstract}
ABSTRAK
Tujuan dari peneitian ini adalah membuat suatu alat evaluasi berbasis komputer yang dapat digunakan untuk mengukur pemahaman konsep Kalkulus mahasiswa. Alat evaluasi ini bisa digunakan secara offline maupun online. Untuk mencapai tujuan itu digunakan model Plomp yang terdiri dari empat tahapan yaitu: fase investigasi awal, fase desain, fase realisasi/konstruksi, fase test, evaluasi dan revisi. Sebelum mengkostruksi instrumen evaluasi dalam bentuk aplikasi, butirbutir soal divalidasi oleh dua orang pakar materi. Butir soal yang valid itulah yang diimport kedalam software Wondershare Quiz Creator untuk menciptakan sebuah prototipe instrumen evaluasi. Prototipe ini kemudian diujicobakan ke mahasiswa secara terbatas untuk melihat kepraktisan penggunaan aplikasi sekaligus menjadi alat evaluasi bagi penelti. Produk terkahir yang dihasilkan merupakan instrumen evaluasi yang valid dan reliabel serta layak digunakan untuk mengukur kemampuan pemahaman konsep Kalkulus Mahasiswa.
\end{abstract}

Kata Kunci: Evaluasi berbasis komputer

\begin{abstract}
This research aims to create a computer-based evaluation tool that could be used to measure students' understanding of the Calculus concept. This evaluation tool could be used offline or online. We use Plomp's model, which consists of four phases: the initial investigation phase, the design phase, the realization/construction phase, the test phase, evaluation, and revision. Before constructing the evaluation instruments in the application form, the items were validated by two material experts. Those valid items were imported into the Wondershare Quiz Creator software to create a prototype evaluation instrument. This prototype was then trialed to students on a limited basis to see the practicality of using the application as well as being an evaluation tool for researchers. The latest product produced was a valid and reliable evaluation instrument and was appropriate to be used to measure the ability to understand the concept of Student Calculus.
\end{abstract}

Keywords: Computer-based evaluation

How to Cite: Nasrum, A. (2020). Pengembangan Instrumen Evaluasi Pemahaman Konsep Kalkulus Berbasis Komputer. Histogram: Jurnal Pendidikan Matematika, 4(1), 78 - 91, doi: http://dx.doi.org/10.31100/histogram.v4i1.540

Permalink/DOI: http://dx.doi.org/10.31100/histogram.v4i1.540

\section{PENDAHULUAN}

Evaluasi pembelajaran merupakan suatu proses yang dilakukan untuk mengetahui kualitas pembelajaran dengan menggunakan instrumen tertentu. Instrumen ini dapat berupa Copyright $($ C 2020, THE AUTHOR (S). This article distributed under the CC-BY-SA-license.

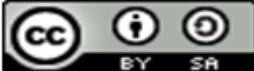


instrumen tes maupun non tes. Proses evaluasi bertujuan untuk mengetahui tingkat penguasaan pembelajaran terhadap materi yang diberikan. Salah satu indikator yang dapat digunakan untuk melihat kualitas dari proses pembelajaran adalah hasil evaluasi para peserta didik.

Evaluasi belajar di Indonesia mulai dari tingkat SD sampai tingkat SMA secara umum ada tiga macam. Evaluasi belajar tengah semester, evaluasi belajar akhir semester dan evaluasi belajar tahap akhir atau biasa disebut dengan Ujian Nasional. Khusus untuk evaluasi belajar tahap akhir (UN) terus mengalami perbaikan dari tahun ketahun. Mulai dari evaluasi bersifat konvensional yang menggunakan kertas hingga berubah menjadi evaluasi berbasis komputer. Evaluasi berbasis Komputer secara bertahap dilakukan di Indonesia sejak tahun 2015. Jumlah sekolah yang mengikuti Ujian nasional berbasis komputer dari tahun ketahun semakin bertambah hingga tahun 2019.

Evaluasi belajar berbasis komputer memiliki banyak kelebihan dibanding evaluasi konvensional. Evaluasi berbasis komputer sebenarnya menguntungkan para guru. Mereka tidak memerlukan banyak waktu untuk memeriksa hasil evaluasi. Hasil dari ujian bisa langsung terlihat setelah ujian selesai dilaksanakan. Sayangnya evaluasi semacam ini hanya diterapkan pada Ujian Nasional. Untuk evaluasi tengah semester dan evaluasi akhir semester di sekolah-sekolah dibawah kementerian pendidikan dan kebudayaan sebahagian besar masih menggunakan cara konvensional.

Tidak hanya di sekolah, di tingkat perguruan tinggi pun demikian. Salah satu contoh perguruan tinggi yang belum menerapkan evaluasi/ujian berbasis komputer adalah Universitas Sembilanbelas November Kolaka khususnya di jurusan pendidikan matematika tempat peneliti mengabdi. Evaluasi tengah dan akhir semester untuk semua mata kuliah di jurusan pendidikan matematika masih berbasis kertas. Padahal evaluasi berbasis komputer sudah banyak dipraktikan oleh para peneliti baik guru maupun dosen.

Hadi Sutopo mengembangakan evaluasi multimedia menggunakan flash, PHP dan My SQL untuk mata kuliah algoritma dan pemrograman (Sutopo, 2011). Susilowati mengembangkan sistem evaluasi berbasis web pada mata pelajaran TIK yang diintegrasikan dengan media e-learning menggunakan web service (Susilowati \& Ashari, 2013). Himah mengembangkan sistem evaluasi berbasis CBT HOT pada mata pelajaran Fisika di SMA menggunakan software XAMPP (Himah et al., 2016). Suyoso mengembangkan instrumen assesmen untuk mata pelajaran Fisika menggunakan aplikasi flash dan quizstar (Suyoso et al., 2017) dan Muhammad mengembangkan instrumen 
evaluasi pada mata pelajaran Sistem Komputer menggunakan e-xam caraka (Muhammad et al., 2018). Instrumen evaluasi seperti ini dapat dikembangkan untuk semua mata pelajaran/mata kuliah. Dalam penelitian ini secara khusus akan dikembangkan instrumen evaluasi berbasis komputer pada mata kuliah Kalkulus yang dapat mengukur kemampuan pemahaman konsep Kalkulus seorang Mahasiswa.

Software yang digunakan oleh beberapa peneliti di atas tergolong sulit untuk seseorang yang tidak punya dasar pemrograman. Namun bukan berarti sistem evaluasi berbasis online tidak bisa dibuat oleh seseorang yang latar belakangnya bukan jurusan komputer. Sekarang banyak tersedia software yang mudah digunakan untuk membuat sistem evaluasi online misalnya wondershare quiz creator, ispring Suite, that Quiz, Kahoot, google form dan lain sebagainya.

Rahayu mengembangkan sistem evaluasi berbasis ICT menggunakan wondershare (Rahayu \& Listiyadi, 2014). Dengan menggunakan model yang sama, Purnamasari juga mengembangkan alat evaluasi berbasis TIK menggunakan software yang sama (Purnamasari \& Rochmawati, 2015). Sama seperti mereka berdua, Pratiwi juga menggunakan software wondershare untuk mengembangkan alat evaluasi berbasis ICT (Pratiwi, 2016). Pengembangan yang mereka lakukan untuk materi tertentu pada jurusan Akuntansi.

Apa yang telah mereka lakukan hampir sama dengan apa yang akan kami kembangkan. Perbedaannya terletak pada materi atau mata kuliahnya. Berbeda materi tentu saja pengembangan butir soalnya juga berbeda. Apalagi yang akan diukur di sini bukan hasil belajar melainkan pemahaman konsep sehingga pengembangan instrumen soalnya berbeda dari yang lain.

Sama seperti tiga peneliti terakhir, peneliti akan menggunakan wondershare quiz creator untuk mengembangkan instrumen evaluasi pada mata kuliah Kalkulus. Pengguna software ini tidak harus menguasai bahasa pemrograman. Software ini memiliki tampilan yang sederhana dan mudah dioperasikan (Candra Rolisca \& Achadiyah, 2014) . Mendukung import file dari word, excel maupun power point sehingga memudahkan dalam penyusunan soal. Terdapat banyak pilihan bentuk soal seperti pilihan ganda, benar-salah, isian singkat dan menjodohkan. Tampilan soal dapat diatur sedemikian rupa sehingga menyerupai ujian nasional atau ujian-ujian lain yang berbasis komputer. Produk luarannya dapat digunakan secara online maupun offline. 


\section{Histogram: Jurnal Pendidikan Matematika, 4 (1), 2020 - 81 Akbar Nasrum}

Penerapan ujian berbasis komputer menguntungkan dosen dalam efisiensi waktu (Dafitri, 2017). Jika evaluasi masih bersifat konvensional (berbasis kertas) maka pemeriksaan hasil ujian bisa berlangsung lama jika jumlah mahasiswa dalam satu kelas cukup banyak. Apalagi lagi jika dosen mengajar di beberapa kelas. Tentu saja pemeriksaan hasil evaluasi akan memakan banyak waktu sementara ketersediaan waktu antara evaluasi akhir dan batas penyetoran nilai sangat terbatas. Desakan pengumpulan nilai mahasiswa dari atasan kadang-kadang membuat pemeriksaan hasil evaluasi tidak maksimal.

Selain itu, evaluasi berbasis konvensional butuh biaya banyak dalam penggandaan soal dan tidak ada jaminan tidak terjadi kebocoran soal dalam penggandaan karena penggandaan soal dikerjakan oleh staff. Untuk mencegah semua ini, para dosen seharusnya mampu untuk mengembangkan soal ujian berbasis komputer. Dosen dituntut untuk aktif, kreatif dan inovatif dalam melaksanakan Tridarma Perguruan Tinggi. Pengembangan soal berbasis komputer merupakan salah satu bentuk inovasi evaluasi pembelajaran. Ujian berbasis komputer juga dapat memperkecil kemungkinan terjadinya kecurangan. Baik masalah kebocoran soal maupun tindak kecurangan saat ujian berlangsung (Dafitri, 2017).

Instrumen evaluasi yang akan dibuat dalam penelitian ini dikhususkan untuk mengukur kemampuan pemahaman konsep Kalkulus mahasiswa. Bukan untuk evaluasi tengah ataupun akhir semester. Dari uraian latar belakang di atas, masalah dalam penelitian ini adalah sebagai berikut: (1) Bagaimana prosedur pengembangan instrumen evaluasi pada mata kuliah Kalkulus? (2) Apakah instrumen evaluasi yang dibuat, layak digunakan sebagai instrumen evaluasi pemahaman konsep Kalkulus?

Tujuan yang ingin dicapai adalah tercipta sebuah instrumen evaluasi berbasis Komputer yang valid dan reliabel, yang dapat mengukur pemahaman Konsep Kalkulus seorang mahasiswa.

\section{METODE PENELITIAN}

Penelitian ini masuk dalam jenis penelitian pengembangan $(R \& D)$. Model yang digunakan adalah model Plomp yang terdiri dari fase investigasi awal, fase desain, fase realisasi/konstruksi, fase test, evaluasi dan revisi (Rochmad, 2012). Alur pelaksanaannya dapat dilihat pada gambar 1 .

Subjek ujicoba dalam penelitian ini adalah dua orang dosen pengampu mata kuliah Kalkulus yang sekaligus bertindak sebagai validator, lima orang mahasiswa semester VII 
pendidikan matematika sebagai kelompok kecil dan seluruh mahasiswa pendidikan matematika semester V kelas A Universitas Sembilanbelas November Kolaka.

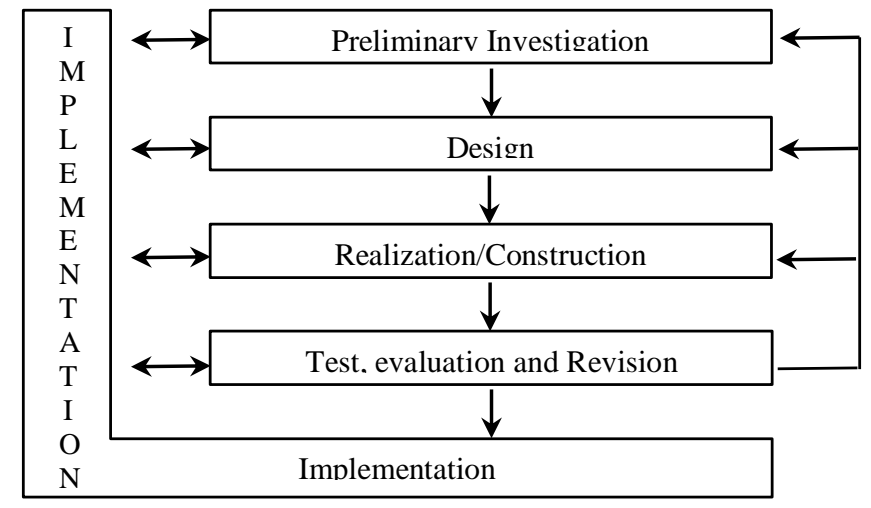

Gambar 1. Model umum untuk memecahkan masalah dalam bidang pendidikan

Instrumen penelitian terdiri dari kisi-kisi soal, lembar validasi instrumen dan sebuah angket untuk respon mahasiswa dan dosen terkait kemudahan pengoperasian aplikasi. Kisi-kisi soal dikembangkan berdasarkan indikator pemahaman matematis dan mengacu pada kurikulum KKNI yang berlaku saat ini. Lembar validasi instrumen dibutuhkan untuk memvalidasi soal-soal yang telah dibuat. Uji valid yang dilakukan dalam penelitian ini adalah validitas konstruk. Tingkat validitas instrumen ditentukan berdasarkan penilaian para ahli. Dalam hal ini, para ahli yang dimaksud adalah dosen-dosen pengampu mata kuliah Kalkulus. Hasil penilaian dari para ahli menjadi dasar dilakukannya perbaikan.

Kriteria soal yang baik adalah soal yang valid dan reliabel. Setelah soal dinyatakan valid oleh tim ahli dilanjutkan dengan menguji tingkat reliabilitas soal menggunakan rumus Spearman-Brown (Eko Putro Widyoko, 2012). Selain itu tingkat kesukaran soal dan daya pembeda juga diukur menggunakan rumus untuk soal-soal objektif (Sundayana, 2014). Tingkat kesukaran soal diukur sebagai dasar pemberian skor pada soal-soal tersebut. Sedangkan daya pembeda diukur untuk melihat soal-soal mana yang bisa membedakan antara mahasiswa yang pandai dan kurang pandai.

Langkah-langkah yang ditempuh untuk membuat suatu instrumen evaluasi pemahaman konsep Kalkulus adalah sebagai berikut

1. Menyusun butir-butir soal berdasarkan indikator yang ada dalam kisi-kisi soal.

2. Memvalidasi butir-butir soal menggunakan lembar validasi oleh Tim Ahli (Dosen pengampu matta kuliah) dan menguji tingkat reliabilitasnya.

3. Merevisi soal-soal sesuai dengan arahan Tim Ahli jika diperlukan. 
4. Mendesain model instrumen termasuk didalamnya pengaturan soal, tampilan luaran hasil dan lainnya.

5. Membuat prototipe instrumen dengan menggunakan software Wondershare Quiz Creator dengan luaran file berextensi exe dan swf.

(Untuk pembuatan instumen offline hanya sampai langkah ini dan yang online lanjut pada langkah berikutnya)

6. Buat website dengan menggunakan google site kemudian upload file swf ke web yang telah dibuat.

7. Salin link Soal kemudian bagikan kepada para subjek penelitian

\section{HASIL DAN PEMBAHASAN}

\section{A. Fase Investigasi Awal}

Dalam tahap ini sebuah masalah didefinisikan. Masalah merupakan kesenjangan antara kondisi ideal yang diharapkan dan fakta yang terjadi dilapangan. Ada beberapa masalah awal yang kami peroleh sehingga berinisiatif untuk melakukan perubahan. Masalah-masalah itu antara lain sebagai berikut:

1. Penginputan nilai akhir mahasiswa ke SIAKAD kadang-kadang tidak tepat waktu (Sistem Akademik Mahasiswa) disebabkan karena banyak hasil evaluasi yang harus diperiksa dan waktu yang tersedia sangat terbatas.

2. Sebagai seorang mahasiswa yang sudah lebih dewasa harusnya sadar bahwa perbuatan menyontek merupakan tidakan kecurangan dan itu dilarang. Ujian berbasis kertas memberikan peluang kerjasama/nyontek yang besar bagi mahasiswa apalagi jika dosen pengawas bukan dosen pengampu mata kuliah.

3. Butuh dana yang banyak untuk penggandaan soal

Berangkat dari masalah ini kami berinisiatif untuk membuat suatu instrumen evaluasi berbasis komputer walaupun dengan fasilitas yang sangat terbatas. Menuju tahap pembuatan instrumennya masih ada beberapa fase yang harus dilalui. Sebelum merealisasikan/mengkosntruksi instrumen terlebih dahulu disusun rencana tertulis atau rencana kerja. Tahap ini disebut dengan tahap desain yang akan dijelaskan pada subba berikut. 
Histogram: Jurnal Pendidikan Matematika, 4 (1), 2020 - 84

Akbar Nasrum

\section{B. Fase Desain}

Desain merupakan cetak biru dari solusi sehingga prosesnya harus teliti. Masalah umum yang digambarkan pada fase pertama harus dibatasi sehingga arah penelitian tidak terlalu luas. Desain solusi yang akan diberikan sebagai berikut:

1. Dari berbagai macam software yang tersedia, dipilih software wondershare quiz creator karena kemudahan dalam penginstalan dan pengoprasiannya.

2. Software-software yang dibutuhkan untuk membuka alat evaluasi yang telah dibuat antara lain: adobe flash dan software puffin untuk browser jika menggunakan android.

3. Instrumen yang dikembangkan adalah instrumen evaluasi Kalkulus. Dalam hal ini khusus untuk instrumen pemahaman konsep kalkulus.

4. Soal yang diberikan adalah soal pilihan ganda dan soal isian.

5. Soal yang tampil pada layar hanya satu nomor dan masing-masing soal diberi batas waktu.

6. Pada tampilan awal, mahasiswa harus menginput Nama dan NIM sebelum mengerjakan soal.

Dalam mengembangkan instrumen soal, ada beberapa instrumen yang digunakan yaitu: Kisi-kisi soal, Lembar validasi Instrumen, Angket respon mahasiswa dan dosen pengampu mata kuliah. Butir-butir soal dibuat berdasarkan indikator/kisi-kisi soal yang dapat dilihat pada tabel 1. Soal-soal yang telah dibuat kemudian diserahkan kepada Tim Ahli untuk diperiksa. Hasil validasi dari Tim ahli dapat dilihat pada tabel 2.

Tabel 1. Indikator Pemahaman Matematis

\begin{tabular}{cl|c}
\hline No & \multicolumn{1}{c|}{ Indikator } & Butir Soal \\
\hline 1 & Menyatakan ulang definisi suatu konsep & 1,2 \\
\hline 2 & Mengidentifikasi keterkaitan antara konsep yang dipelajari & 3,4 \\
\hline 3 & Memberikan contoh atau contoh kontra dari konsep yang & 5 \\
\hline 4 & Mengaitkan berbagai konsep dalam matematika & 6 \\
\hline 5 & Mengenal syarat yang menentukan suatu konsep & 7 \\
\hline 6 & Mengembangkan syarat perlu dan syarat perlu dan/atau cukup & 8,9 \\
\hline 7 & Menyajikan konsep dalam berbagai macam bentuk representasi & 10 \\
\hline 8 & Menerapkan konsep secara logis & $11,12,13,14$ \\
\hline
\end{tabular}

(Sumber: Hendriana et al., Tahun: 2017) 
Histogram: Jurnal Pendidikan Matematika, 4 (1), 2020 - 85

Akbar Nasrum

Tabel 2. Hasil Validasi Butir Soal oleh Tim Ahli

\begin{tabular}{clcc}
\hline \multirow{2}{*}{ No } & \multirow{2}{*}{ Aspek } & \multicolumn{2}{c}{ Tim Validator } \\
\cline { 3 - 4 } & & Pakar 1 & Pakar 2 \\
\hline 1 & Materi & 4,11 & 3,91 \\
\hline 2 & Konstruksi & 3,95 & 4,12 \\
\hline 3 & Bahasa & 3,89 & 4,00 \\
\hline & Rata-rata & 3,98 & 4,01 \\
\hline
\end{tabular}

(Sumber: Data Primer, Tahun: 2019)

Pada tabel 2 diperoleh angka rata-rata skor hasil penilaian pakar 1 dan pakar 2 adalah 3,99 (skala 5). Angka ini menunjukkan bahwa butir soal yang telah disusun untuk pembuatan instrumen sudah memenuhi kriteria valid (Farman \& Yusranto, 2018). Setelah instrumen soal diperiksa dan dinyatakan valid, dilanjutkan dilanjutkan dengan uji reliabilitas. Hasil uji reliabilitas menggunakan Spearman-Brown dapat dilihat pada tabel 3.

Tabel 3. Hasil uji reliabel menggunakan SPSS

\begin{tabular}{|c|c|c|c|c|}
\hline No. & Jenis Uji Reliabilitas & Teknik & Keterangan & Nilai \\
\hline \multirow[t]{5}{*}{1} & \multirow[t]{5}{*}{ Cronbach's Alpha } & \multirow[t]{2}{*}{ Bagian 1} & Nilai & 0,41 \\
\hline & & & Jumlah & 7 \\
\hline & & \multirow[t]{2}{*}{ Bagian 2} & Nilai & 0,75 \\
\hline & & & Jumlah & 7 \\
\hline & & \multicolumn{2}{|c|}{ Jumlah item Keseluruhan } & 14 \\
\hline 2 & Korelasi antara belahan & & & 0,60 \\
\hline \multirow[t]{2}{*}{3} & Koefisien Spearman Brown & \multicolumn{2}{|c|}{ Jumlah item sama } & 0,75 \\
\hline & & \multicolumn{2}{|c|}{ Jumlah item berbeda } & 0,75 \\
\hline 4 & Koefisien Belah Dua Guttma & & & 0,74 \\
\hline
\end{tabular}

Keterangan : bagian (a) adalah item nomor 1, 2, 3, 4, 5, 6 sedangkan bagian (b) adalah item nomor $8,9,10,11,12,13$, dan 14

(Sumber: Data Primer, Tahun: 2019)

Nilai indeks reliabilitas instrumen berdasarkan tabel adalah 0,75. Nilai ini lebih besar dari nilai kritis $r$ product moment yaitu 0,71 . Oleh karena itu butir soal yang valid dinyatakan reliabel. Selanjutnya hasil uji taraf kesukaran dan daya pembeda soal dapat dilihat pada tabel 4 
Histogram: Jurnal Pendidikan Matematika, 4 (1), 2020 - 86

Akbar Nasrum

Tabel 4. Hasil uji Daya Pembeda (DP) dan Taraf Kesukaran (TK)

\begin{tabular}{ccccclcl}
\hline Soal & SA & SB & IA & DP & Keterangan & TK & Keterangan \\
\hline 1 & 9 & 7 & 9 & 0,22 & Cukup & 0,89 & Mudah \\
\hline 2 & 8 & 4 & 9 & 0,44 & Baik & 0,67 & Sedang \\
\hline 3 & 3 & 0 & 9 & 0,33 & Cukup & 0,17 & Sukar \\
\hline 4 & 7 & 2 & 9 & 0,56 & Baik & 0,50 & Sedang \\
\hline 5 & 3 & 3 & 9 & 0,00 & Sangat Jelek & 0,33 & Sedang \\
\hline 6 & 7 & 3 & 9 & 0,44 & Baik & 0,56 & Sedang \\
\hline 7 & 6 & 4 & 9 & 0,22 & Cukup & 0,56 & Sedang \\
\hline 8 & 6 & 3 & 9 & 0,33 & Cukup & 0,50 & Sedang \\
\hline 9 & 8 & 0 & 9 & 0,89 & Sangat baik & 0,44 & Sedang \\
\hline 10 & 5 & 3 & 9 & 0,22 & Cukup & 0,44 & Sedang \\
\hline 11 & 7 & 1 & 9 & 0,67 & Baik & 0,44 & Sedang \\
\hline 12 & 6 & 0 & 9 & 0,67 & Baik & 0,33 & Sedang \\
\hline 13 & 6 & 2 & 9 & 0,44 & Baik & 0,44 & Sedang \\
\hline 14 & 0 & 0 & 9 & 0,00 & Sangat Jelek & 0,00 & Sangat Sukar \\
\hline (Sumber: Data Primer, Tahun: 2019$)$ & &
\end{tabular}

Dari empat belas soal yang tersedia, masing-masing satu butir soal terkategori mudah, sukar dan sangat sukar. Selebihnya berada dalam kategori tingkat kesukaran “sedang". Selanjutnya untuk daya pembeda ada dua soal yang daya pembedanya sangat jelek yaitu soal yang terkategori sangat sukar dan satu soal dengan kategori sedang. Selain dari dua soal ini, sisanya mempunyai daya pembeda cukup, baik dan sangat baik. Fase berikutnya yaitu fase realisasi/konstruksi.

\section{Fase Konsturksi}

Pada tahap ini dimulai pembuatan alat evaluasi berbasis komputer. Hal pertama yang harus dilakukan adalah mendownload dan menginstal software Wondershare Quiz Creator

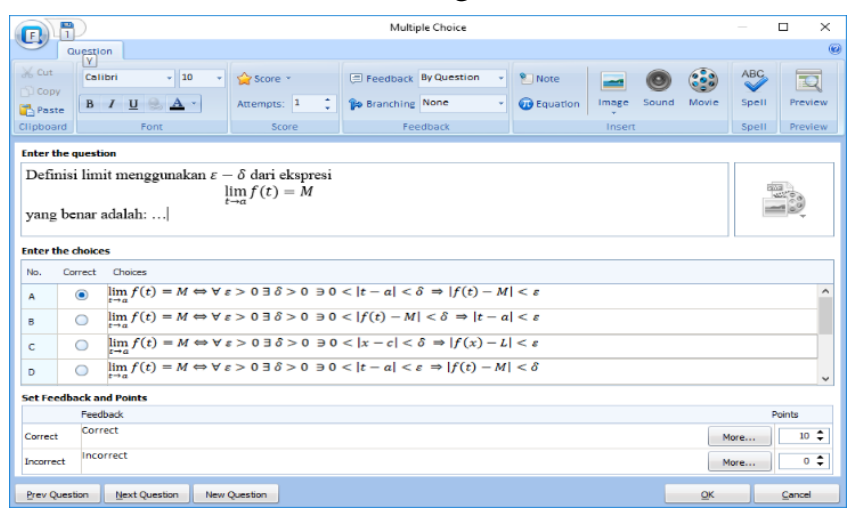

Gambar 2. Proses Editing Soal pada Wondershare 
pada laptop atau PC. Setelah terinstal, salin semua soal yang valid ke template word yang sudah disediakan oleh software ini. Setelah itu, import file word yang berisi soal ke aplikasi wonderhare dan dilanjutkan dengan pengeditan. Proses editing ini diperlukan karena soal yang diimport dari file word belum tentu semuanya tertata dengan benar pada tempatnya.

Setelah proses editing selesai dilanjutkan dengan pengaturan properti kuis meliputi Quiz Information, Quiz Settings, Quiz Result, Quiz Settings dan Other.

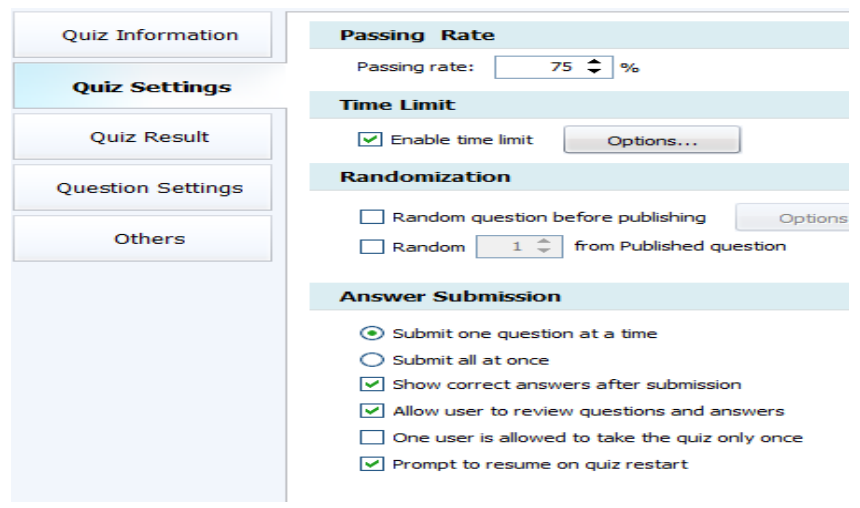

Gambar 3. Bagian-bagian properti kuis

Quiz Information berisi data tentang pembuat soal, nama kuis dan informasi data mahasiswa yang dibutuhkan. Quiz Settings berisi tentang pengaturan waktu dan pengaturan umpan balik dari jawaban, termasuk pengaturan jumlah randomisasi soal. Quiz Result berisi umpan balik hasil jawaban. Quiz Settings berisi pengaturan tentang pengacakan soal dan jawaban. Terakhir adalahbagian Other yang berisi pengaturan tentang proteksi file yang telah dibuat.

Setelah semua selesai dilanjutkan dengan proses Publish. Proses ini memberikan beberapa pilihan luaran. Ada web, $L M S$, $c d / e x e$ dan versi word. Jika ingin memperoleh aplikasi ujian dalam bentuk offline, pilih cd/exe. Hasilnya berupa file aplikasi dengan extensi exe. File ini dapat dibuka dengan menggunakan adobe flash. Untuk memperoleh aplikasi ujian berbasis online, pilih web. Luarannya berupa file $s w f$, dapat dibuka dengan swf Player atau software browser asalkan adobe flash playernya sudah terinstal. Ujian berbasis online menggunakan HP Android juga bisa dilakukan dengan terlebih dahulu, harus mendownload dan menginstal aplikasi puffin browser. Setelah proses publish dilakukan, aplikasi ujian berbasis komputer sudah bisa digunakan. Tampilan muka aplikasi offline dapat dilihat pada gambar 4 dan contoh prototipenya dapat diunduh di sini https://drive.google.com/open?id=1 a6xm8-MsBPPaGX5V9iP_ZAdfrkduKoRG 
Histogram: Jurnal Pendidikan Matematika, 4 (1), 2020 - 88

Akbar Nasrum

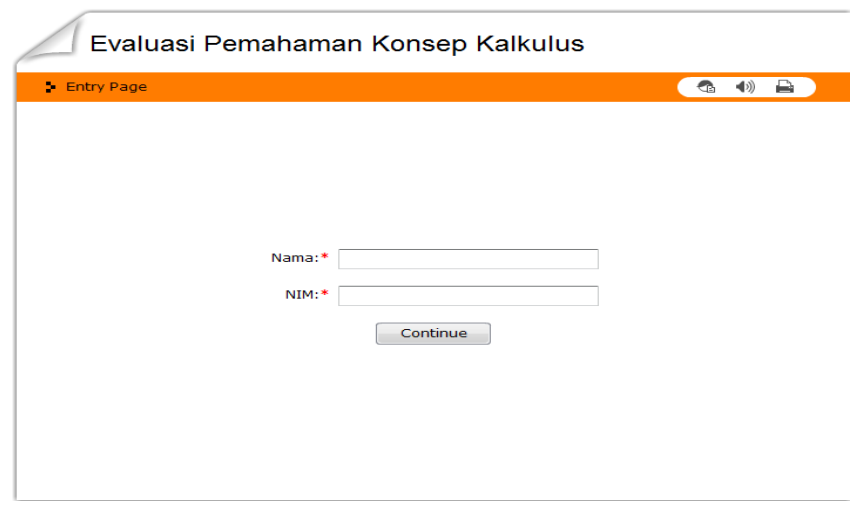

Gambar 4. Halaman muka Instrumen evaluasi berbasis komputer

Lain halnya dengan ujian aplikasi online. Hasil produk berupa file $s w f$ tidak bisa langsung digunakan. Agar bisa digunakan, file ini harus diupload ke web atau ke blog. Dalam penelitian ini kami membuat website khusus untuk ujian menggunakan google sites. Prosesnya sangat sederhana dan tidak butuh biaya. Setelah jadi, file ujian diupload ke web dan hasilnya dapat dilihat dengan mengklik lingk pada kotak di bawah (Tekan tombol ctrl pada keyboard sambil mengklik link.

https://ca996e05-a-62cb3a1a-ssites.googlegroups.com/site/ujiankalkulus/Konsep\%20kalkulus.swf?attachauth=ANoY7coYS3 HiCbcw2CBsdAl2c_yMxBa4RLFGeaPOzYe1Rga3q42o3wQNLqo5o8NRjfS8ZLGv7wFqB7S acQwxTOKLF3erQos8XiXWpuPDynQ37rFzTCHdAiutSLrbxX1kvJkvkkLmK9in2tLyfhJFjY EX7ih5fh01csoudJRHYCr 9Y-

r7_t9hNHVEta_H8NcweWfquw5U416fcbd7S_Uo1H0EIXmn23rQ\%3D\%3D\&attredirects=0

\section{Fase Test, Evaluasi dan Revisi}

Produk hasil pengembangan pada tahap I diberi nama prototipe I dan produk hasil revisi disebut prototipe II, prototipe III dan seterusnya tergantung banyaknya revisi. Sebelum digunakan pada kelas sesungguhnya, prototipe 1 diujicobakan kembali ke dosen pengampu mata kuliah serta ke lima mahasiswa tingkat atas untuk melihat kerumitan atau kepraktisan penggunaan aplikasi. Selain itu, hasil uji coba pada pada mahasiswa dengan jumlah terbatas ini juga berfungsi sebagai alat evaluasi. Boleh jadi dalam proses pengetikan soal sampai tahap publish terdapat kekeliruan yang perlu diperbaiki. Dari hasil uji coba diperoleh beberapa revisi yaitu sebagai berikut:

1. Instrumen tes terdiri dari 14 butir soal. 10 nomor pilihan ganda, 2 nomor Benar-Salah dan 2 nomor (short essay) uraian singkat. Setelah uji coba, ternyata dua nomor uraian 
singkat tidak bisa dinilai dalam sistem. Oleh karena itu diganti dengan soal fill in the blank.

2. Ada beberapa kesalahan pengetikan matematika dan kesalahan jumlah pilihan jawaban pada prototipe I yang perlu diperbaiki

3. Pada prototipe I petunjuk pengerjaan soal belum tersedia sehingga ditambahkan petunjuk pada prototipe II

4. Pada prototipe I, setelah semua soal sudah dikerjakan, peserta dapat melihat kembali soal dan kunci jawabannya. Koreksi hasil jawaban yang benar dihilangkan pada prototipe II karena soal akan digunakan kembali untuk revisi. Hasil angket respon mahasiswa dan dosen pengampu mata kuliah dapat dilihat pada tabel 5:

Tabel 5. Respon Mahasiswa dan dosen terhadap penggunaan instrumen pada prototipe I

\begin{tabular}{llcccc}
\hline No & \multicolumn{1}{c}{ Indikator yang dinilai } & Skor & $\begin{array}{c}\text { Skor } \\
\text { maks }\end{array}$ & $\begin{array}{c}\text { Presentase } \\
(\mathbf{\%})\end{array}$ \\
\hline 1 & $\begin{array}{l}\text { Tanggapan terhadap kemudahan pengoprasian } \\
\text { aplikasi }\end{array}$ & 20 & 25 & 80 \\
\hline 2 & Ketertarikan & 21 & 25 & 84 \\
\hline 3 & Tanggapan terhadap hasil evaluasi & 19 & 25 & 76 \\
\hline 4 & $\begin{array}{l}\text { Tanggapan dosen terhadap modifikasi untuk } \\
\text { pengembangan soal }\end{array}$ & 19 & 25 & 76 \\
\hline & Jumlah & 82 & 100 & 316 \\
\hline & Rata-rata & & 79 &
\end{tabular}

(Sumber: Data Primer, Tahun: 2019)

Dari tabel 4 diperoleh nilai rata-rata skor yang menunjukkan bahwa secara umum hasil respon mahasiswa dan dosen terkategori baik (Iqbal et al., 2018). Dua indikator pertama yaitu tanggapan terhadap kemudahan pengoprasian dan ketertarikan mahasiswa dan dosen terhadap penggunaan aplikasi diatas $80 \%$. Dua poin terakhir kurang dari $80 \%$ namun masih terkategori baik.

Setelah proses revisi selesai, prototipe II dipublish kembali dan diujicoba pada kelas A semester 5 pendidikan matematika sebagai bentuk implementasi. Instrumen ini memberikan hasil yang sesuai dengan prediksi dosen yang mengajar di kelas. Hanya sekitar $21,05 \%$ mahasiswa yang tingkat pemahamannya berada dalam kategori baik, 42,11\% berada dalam kategori sedang dan 36,84\% masih perlu banyak belajar. Prototipe II yang digunakan ini merupakan prototipe final yang dinyatakan layak digunakan dalam evaluasi pemahaman konsep Kalkulus Berbasis Komputer. 
Histogram: Jurnal Pendidikan Matematika, 4 (1), 2020 - 90

Akbar Nasrum

\section{KESIMPULAN DAN SARAN}

\section{A. Kesimpulan}

Proses penelitian mulai dari fase investigasi awal sampai fase akhir menghasilkan suatu produk yaitu Instrumen evaluasi pemahaman konsep Kalkulus yang dikemas dalam bentuk aplikasi offline maupun online. Instrumen ini dinyatakan valid untuk digunakan sebagai alat ukur kemampuan pemahaman konsep Kalkulus dan sangat membantu para dosen karena tidak membutuhkan proses yang lama untuk mendapatkan hasil tes.

\section{B. Saran}

Produk yang dihasilkan dalam penelitian ini merupakan langkah awal untuk memperbaiki proses evaluasi di Universitas November Kolaka. Untuk penelitian selanjutnya kami akan membuat produk serupa tetapi untuk evaluasi hasil belajar Kalkulus secara keseluruhan.

\section{DAFTAR PUSTAKA}

Candra Rolisca, R. U., \& Achadiyah, B. N. (2014). Pengembangan Media Evaluasi Pembelajaran Dalam Bentuk Online Berbasis E-Learning Menggunakan Software Wondershare Quiz Creator Dalam Mata Pelajaran Akuntansi Sma Brawijaya Smart School (Bss). Jurnal Pendidikan Akuntansi Indonesia, 12(2). https://doi.org/10.21831/jpai.v12i2.2706

Dafitri, H. (2017). Pemanfaatan Wondershare Quiz Creator Dalam Tes Berbasis Komputer. QUERY : Jurnal Sistem Informasi, 01(01), 8-18.

Eko Putro Widyoko. (2012). Teknik Penyusunan Instrumen Penelitian. Pustaka Pelajar.

Farman, \& Yusranto. (2018). Pengembangan Desain Pembelajaran Berbasis Problem Posing Dalam Upaya Meningkatkan Kemampuan Penalaran Konsep Lingkaran Pada SIswa SMP Kelas VIII. Jurnal Karya Pendidikan Matematika, 2, 20-27.

Hendriana, H., Eti Rohaeti, E., \& Sumarmo, U. (2017). Hard Skills dan Soft Skills Matematik Siswa. Refika Aditama.

Himah, F., Sudarti, S., \& Subiki, S. (2016). Pengembangan Instrumen Tes Computer Based Test-Higherorder Thinking (Cbt-Hot) Pada Mata Pelajaran Fisika Di Sma. Jurnal Pembelajaran Fisika Universitas Jember, 5(1), 89-95.

Iqbal, W. M. G., Fadhilah, R., \& Hardiati, D. (2018). Pengembangan Alat Evaluasi Berbasis Wondershare Quiz Creator Pada Materi Koloid Kelas XI di SMA Koperasi Pontianak. Ar-Razi Jurnal Ilmiah, 6(1), 11-15.

Muhammad, A., Mappeasse, M. Y., \& Arfandi, A. (2018). Pengembangan Instrumen Evaluasi Pembelajaran Pada Mata Pelajaran Sistem Komputer Berbasis E-Xam Caraka Di SMK Negeri 1 Bantaeng. Jurnal Pendidikan, 1(2), 26-29.

Pratiwi, V. (2016). Pengembangan Alat Evaluasi Pembelajaran Berbasis ICT Menggunakan Wondershare Quiz Creator Pada Materi Penyusutan Aset Tetap. Jurnal Pendidikan Akuntansi (JPAK), 4(1), 1-7.

Purnamasari, A., \& Rochmawati. (2015). Pengembangan Alat Evaluasi Pembelajaran Berbasis Teknologi Informasi Dan Komunikasi Dengan Wondershare Quiz Creator 


\section{Histogram: Jurnal Pendidikan Matematika, 4 (1), 2020 - 91 Akbar Nasrum}

Materi Sistem Penilaian Persediaan. Jurnal Pendidikan, 03(01), 1-10.

Rahayu, E. E., \& Listiyadi, A. (2014). Pengembangan Alat Evaluasi Pembelajaran Berbasis Information and Communication Technologies (ICT) pada Materi Mengelola Dokumen Transaksi. Jurnal Pendidikan Akutansi, 2(2), 1-7.

Rochmad. (2012). Desain Model Pengembangan Perangkat Pembelajaran Matematika. Kreano: Jurnal Matematika Kreatif-Inovatif, 3(1), 59-72. https://doi.org/10.15294/kreano.v3i1.2613

Sundayana, R. (2014). Statistika Penelitian Pendidikan. Alfabeta.

Susilowati, E. B., \& Ashari, A. (2013). Pengembangan Sistem Evaluasi Kegiatan Belajar Mengajar Berbasis Web Studi Kasus: di SMA Negeri 1 Surakarta. IJCCS (Indonesian Journal of Computing and Cybernetics Systems), 7(2), 199-208. https://doi.org/10.22146/ijccs.3360

Sutopo, H. (2011). Pengembangan Evaluasi Pembelajaran Berbasis Multimedia Dengan Flash, Php, Dan Mysql. Jurnal Informatika, 11(1), 79-85. https://doi.org/10.9744/informatika.11.1.1-7

Suyoso, S., Istiyono, E., \& Subroto, S. (2017). Pengembangan Instrumen Asesmen Pengetahuan Fisika Berbasis Komputer Untuk Meningkatkan Kesiapan Peserta Didik Dalam Menghadapi Ujian Nasional Berbasis Komputer. Jurnal Pendidikan Matematika Dan Sains, 5(1), 89-97. https://doi.org/10.21831/jpms.v5i1.12461 